JAMA Facial Plastic Surgery | Original Investigation

\title{
Computer-Aided Design, 3-D-Printed Manufacturing, and Expert Validation of a High-fidelity Facial Flap Surgical Simulator
}

Allison R. Powell, MSE; Sudharsan Srinivasan, MSE; Glenn Green, MD; Jennifer Kim, MD; David A. Zopf, MD, MS

IMPORTANCE Facial flap procedures may be difficult for surgical trainees to conceptualize and challenging for supervising surgeons to allow entrustment early in training. Simulation outside of the operating room may accelerate and enhance the surgical education experience.

OBJECTIVE To design and manufacture a 3-dimensional (3-D)-printed, multilayer, anatomically accurate facial flap model for use in surgical education.

DESIGN, SETTING, AND PARTICIPANTS In this multicenter validation study, a 3-D-printed facial flap simulator was designed from a computed tomographic (CT) scan and manufactured for low-cost, high-fidelity simulation. Expert otolaryngology-head and neck surgeon feedback was acquired through surgical rehearsal and performance of 8 local facial flap procedures on the facial flap simulator by 7 otolaryngologists fellowship trained in facial plastic surgery.

MAIN OUTCOMES AND MEASURES Likert scale surveys were made based on evaluation criteria categorized into domains of realism, experience, and applicability of the simulator. Measures of central tendency, variability, and confidence intervals were generated to evaluate the outcomes.

RESULTS Seven expert otolaryngology-head and neck surgeons completed a Likert scale evaluation survey containing quantitative analysis of 6 questions on physical attributes, 12 questions on realism, 8 questions on experience, and 4 questions on the applicability of the simulator. All expert surgeons were additionally fellowship trained in facial plastic surgery with their mean years in practice being 11.9. Overall evaluation demonstrated valuable ability of the simulator for medical education with suggestions for future directions. Importantly, the simulator was rated on a scale of 1 (no value) to 4 (great value) as 3.86 as a training tool, 3.57 as a competency evaluation tool, and 3.43 as a rehearsal tool.

CONCLUSIONS AND REVELANCE Expert experience with the local facial flap simulator was rated highly for realism, experience, performance, and usefulness. With slight refinement, the model has strong potential for broad use in training in otolaryngology-head and neck surgery and facial plastic surgery.

LEVEL OF EVIDENCE NA.
JAMA Facial Plast Surg. 2019;21(4):327-331. doi:10.1001/jamafacial.2019.0050

Published online April 25, 2019.

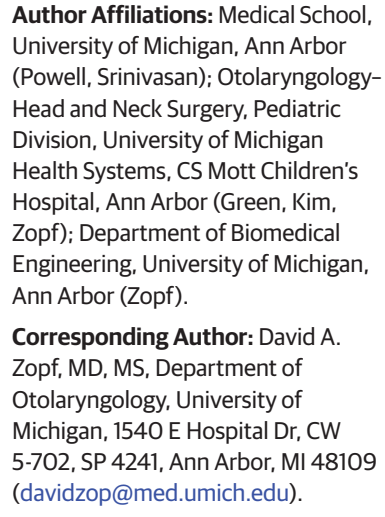

Author Affiliations: Medical School, University of Michigan, Ann Arbor (Powell, Srinivasan); OtolaryngologyHead and Neck Surgery, Pediatric Division, University of Michigan Health Systems, CS Mott Children's Hospital, Ann Arbor (Green, Kim, Zopf); Department of Biomedical Engineering, University of Michigan, Ann Arbor (Zopf).

Corresponding Author: David A Zopf, MD, MS, Department of Otolaryngology, University of Michigan, 1540 E Hospital Dr, CW 5-702, SP 4241, Ann Arbor, MI 48109 (davidzop@med.umich.edu). 
$\mathrm{F}$ acial-adjacent tissue transfers or local facial flap procedures are a cornerstone of facial plastic surgery and otolaryngology-head and neck surgery. They often encompass complex geometric conceptual understanding. Entrustment of when a trainee is skilled enough to complete the procedure is variable. Outcomes are highly dependent on experience. As such, it is difficult for trainees to gain experience and confidence early in training. In addition, a patient under local anesthesia can have increased stress and anxiety knowing a trainee is learning and performing their facial flap procedure. Because of this, local facial flap procedure training relies heavily on gaining confidence and expertise on other areas of the body before operating on a patient owing to the sensitivity of operating on a patient's face. ${ }^{1-3}$ However, other areas of the body do not emulate the facial skin characteristics or consider secondary distortion of critical adjacent regions such as the lower eyelid.

Opportunities for other learning modalities are possible, including animal models, virtual reality, and cadaveric specimens for medical education. Although physical models such as rat, bovine, ovine, or human cadavers can be used, each has distinct disadvantages. ${ }^{4}$ These models lack anatomical landmarks for flap-specific learning, differ considerably in skin characteristics, and carry their own biologic risks and cost. Animal and human remains cannot be retained, archived, or reassessed for further evaluation and assessment of progress after the task is complete. With technology allowing for increased opportunity to virtually simulate procedures, there has been new research in augmented reality surgical simulators. Local facial flap simulation has been successfully compared to textbook learning, demonstrating the importance of simulation in this field. ${ }^{5}$ Often, virtual reality may benefit a learner early, but does not provide the tactile feedback necessary to fully appreciate flap design and mechanics.

Surgical simulators allow for physical, hands-on learning of a procedure and have played a more recent role across some surgical specialties such as orthopedic surgery, neurosurgery, and otolaryngology. ${ }^{6-9}$ Three-dimensional (3-D) printing specifically has played a part recently in simulation, patientspecific models for operative planning, and device development. ${ }^{10}$ Three-dimensional printing allows for simulation design based on imaging data and with supportive feedback from physicians themselves can lead to an iterative design for creating optimal models for education. ${ }^{11,12}$

To address the need for higher fidelity and anatomically accurate simulation for physical practice, we developed a 3-Dprinted, low-cost, anatomically accurate local facial flap model. Physical repetition using standard surgical equipment to solidify skills can be achieved on the simulator. With skin and adipose layers, the model allows for undermining of the skin, design of flap, and surgical practice in a zero-risk environment.

\section{Methods}

Simulator Development

A computed tomographic (CT) scan was used to model anatomically accurate facial features such as the brow line, nasal

\section{Key Points}

Question Can computer-aided design and 3-dimensional printing be leveraged to develop a novel high-fidelity surgical simulator for facial flap simulation?

Findings Seven expert otolaryngologist-head neck surgeons with fellowship training in facial plastic surgery validated the facial local flap simulator with high evaluations for physical attributes, realism, performance, experience, and value as a simulator.

Meaning Expert validation suggests that the simulator may be useful for medical education during residency training.

Figure 1. Computer-Aided Design (CAD) Representation of Facial Local Flap Simulator With CAD of Manufacturing Assembly

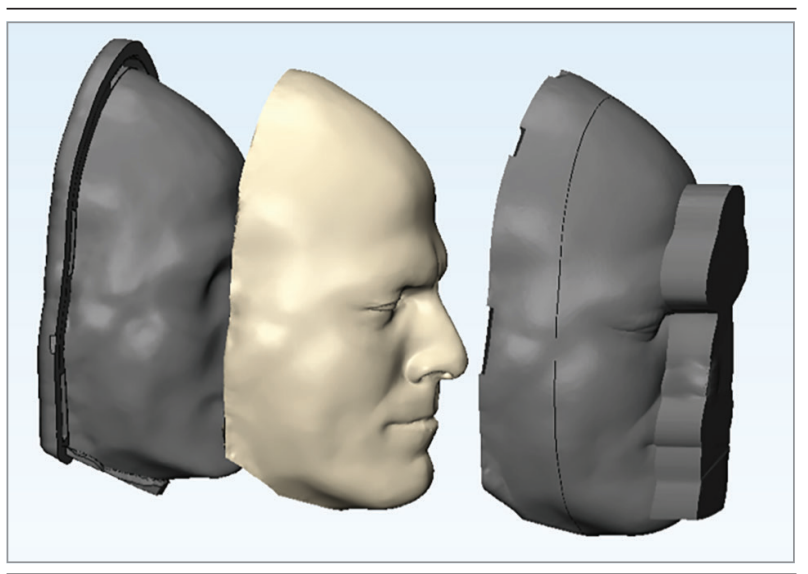

Two-piece manufacturing system in dark gray is 3-dimensionally printed. The $\tan$ facial feature is the representation of the facial flap. Liquid silicone that is poured between the 2-piece manufacturing system cures into the shape of the tan image.

features, lip, and cheek regions. Computer-aided design (CAD) software (Materialise Mimics, 3-Matic) allowed for segmentation and modeling of the facial composite. A 3-mm depth of skin and a 6-mm depth of fat was implemented for the model. A negative casting mold was designed to allow for skincolored silicone to be poured and cured in $60^{\circ} \mathrm{C}$ for 4 hours to complete the model (Figure 1). A yellow adipose layer made of 10 shore silicone was added as a second layer. Various skin tones were produced for the models using a range of pigment tones. The multilayer model was completed by placing it onto a 3-D-printed base composed of polylactic acid for use by the validation experts.

\section{Study Design}

The 31-question survey was developed to gain insight into physical attributes, realism of experience, performance, and applicability of the simulator. Experts were asked to perform 8 types of facial flaps. Four- and 5-point Likert scales, defined in Table 1, were used in this evaluation. Established methods of medical education survey development were implemented to design and evaluate the survey, including expert feedback before use. ${ }^{13}$ Higher ratings suggest evaluators had a higher perceived value of the questioned aspect of the simulator. 


\begin{tabular}{|c|c|c|c|c|c|}
\hline \multirow{2}{*}{$\begin{array}{l}\text { Survey Domain } \\
\text { Physical } \\
\text { attributes; } \\
\text { realism of } \\
\text { experience }\end{array}$} & \multicolumn{5}{|c|}{ Definitions of Scale } \\
\hline & $\begin{array}{l}\text { (NR) } \\
\text { Do not know }\end{array}$ & $\begin{array}{l}(1) \\
\text { Not at all } \\
\text { realistic }\end{array}$ & $\begin{array}{l}\text { (2) } \\
\text { Somewhat realistic, } \\
\text { needs significant } \\
\text { improvement }\end{array}$ & $\begin{array}{l}\text { (3) } \\
\text { Adequate realism } \\
\text { as is, needs } \\
\text { improvement }\end{array}$ & $\begin{array}{l}\text { (4) } \\
\text { Highly } \\
\text { realistic, } \\
\text { no changes } \\
\text { needed }\end{array}$ \\
\hline $\begin{array}{l}\text { Ability to } \\
\text { perform tasks }\end{array}$ & $\begin{array}{l}\text { (1) } \\
\text { Too difficult } \\
\text { to perform }\end{array}$ & $\begin{array}{l}(2) \\
\text { Very difficult } \\
\text { to perform }\end{array}$ & $\begin{array}{l}\text { (3) } \\
\text { Difficult to } \\
\text { perform }\end{array}$ & $\begin{array}{l}\text { (4) } \\
\text { Somewhat easy } \\
\text { to perform }\end{array}$ & $\begin{array}{l}\text { (5) } \\
\text { Very easy } \\
\text { to perform }\end{array}$ \\
\hline Value & $\begin{array}{l}\text { (NR) } \\
\text { Do not know }\end{array}$ & $\begin{array}{l}\text { (1) } \\
\text { No value }\end{array}$ & $\begin{array}{l}\text { (2) } \\
\text { Little value }\end{array}$ & $\begin{array}{l}\text { (3) } \\
\text { Some value }\end{array}$ & $\begin{array}{l}\text { (4) } \\
\text { A great } \\
\text { deal of value }\end{array}$ \\
\hline Relevance & $\begin{array}{l}\text { (NR) } \\
\text { Do not know }\end{array}$ & $\begin{array}{l}\text { (1) } \\
\text { No relevance }\end{array}$ & $\begin{array}{l}\text { (2) } \\
\text { Little relevance }\end{array}$ & $\begin{array}{l}\text { (3) } \\
\text { Some relevance }\end{array}$ & $\begin{array}{l}\text { (4) } \\
\text { A great } \\
\text { deal of } \\
\text { relevance }\end{array}$ \\
\hline $\begin{array}{l}\text { Global } \\
\text { improvement }\end{array}$ & $\begin{array}{l}\text { (1) } \\
\text { This simulation } \\
\text { requires a } \\
\text { number of } \\
\text { tweaks before } \\
\text { it can be } \\
\text { considered for } \\
\text { use in facial } \\
\text { flap training }\end{array}$ & $\begin{array}{l}\text { (2) } \\
\text { This simulation } \\
\text { requires small } \\
\text { tweaks before } \\
\text { it can be } \\
\text { considered } \\
\text { for use in facial } \\
\text { flap training }\end{array}$ & $\begin{array}{l}\text { (3) } \\
\text { This form of the } \\
\text { simulation can } \\
\text { be used as is for } \\
\text { facial flap training, } \\
\text { but could be } \\
\text { improved slightly }\end{array}$ & $\begin{array}{l}\text { (4) } \\
\text { This form of the } \\
\text { simulation can be } \\
\text { used as is for } \\
\text { facial flap } \\
\text { training with } \\
\text { no improvements } \\
\text { made }\end{array}$ & \\
\hline
\end{tabular}

\section{Results}

Evaluation of 6 physical attributes, 12 realism of experience, 8 performance, 3 questions on application, and 1 question on improvement were completed by 7 expert facial plastic fellowship trained otolaryngology-head and neck surgeons. Additional written, free-form comments were collected about improvement. Expert evaluators had a mean of 11.9 years of practice, with a mean of 106.8 local facial flaps performed in the past year. Of the local facial flaps evaluated, bilobed flaps were the most common type performed throughout their careers, with pinwheel as least common. The final facial local flap simulator was provided to the experts and they completed the validation using the simulator (Figure 2). High ratings across all of the domains suggest similarity between the simulator and surgical procedures necessary for use in medical education (Table 2).

The highest ratings for physical attributes domain are for overall facial composite and overall facial landmarks with a mean (SD) of $3.86(0.38)$. The highest ratings for realism of experience are for O-T and pinwheel with a mean (SD) of 3.43 (0.53). For performance, the highest ratings with a mean (SD) of 4.57 (0.53) for Z-plasty, V-Y, rectangular advancement, O-T, and pinwheel. Under value domain, the highest rated was for simulator as a training tool with a mean (SD) of 3.86 (0.38) followed by simulator as a competency evaluation tool with a mean (SD) of 3.57 (0.53).

The material cost of the small facial flap was $\$ 4.61$, whereas the large flap cost $\$ 8.14$ in silicone. Labor and manufacturing cost was not included.

\section{Discussion}

This simple yet realistic model has great potential for learners of local facial flaps to gain an understanding of the planning,

Figure 2. Completed Facial Flap Model Exhibiting Usage and Characteristics

A Facial flap simulator B Facial flap simulator
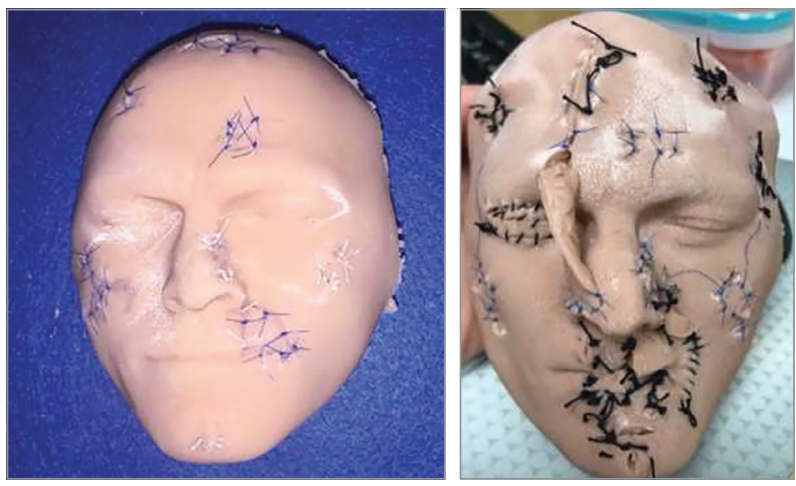

C Anterior and posterior view

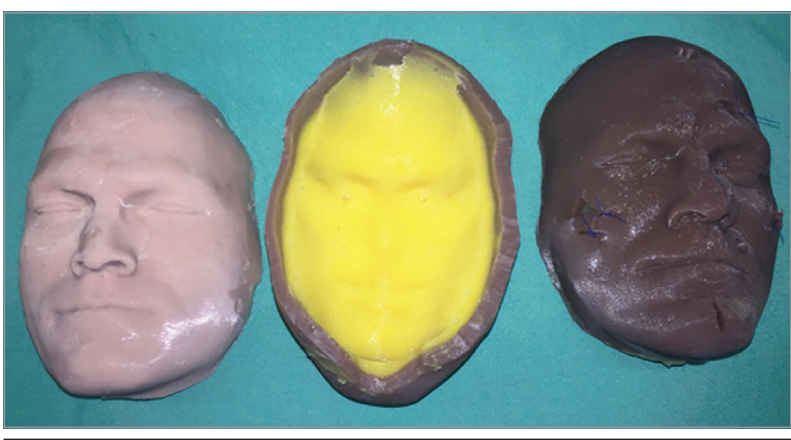

A and B, Facial local flap simulator in use for procedures evaluated in course. C, Facial local flap simulator with anterior and posterior view highlighting the subcutaneous adipose layer thickness relative to cutaneous layer. Further demonstration of dynamic range of simulator includes ability to provide various pigment shades for facial representation.

geometry, and mechanics of local skin flaps on the face and for practicing facial local flap procedures. High ratings for value 


\begin{tabular}{|c|c|c|c|c|}
\hline Faci & Flap Survey Questions & Mean (SD) & Total & $(95 \% \mathrm{Cl})$ \\
\hline \multicolumn{5}{|c|}{ Physical Attributes (Domain Overall Mean $=3.29$ ) } \\
\hline 1 & Overall facial composite & $3.86(0.38)$ & 4 & $(3.48-4.00)$ \\
\hline 2 & Overall facial landmarks & $3.86(0.38)$ & 4 & $(3.48-4.00)$ \\
\hline 3 & Skin depth/density & $2.71(0.95)$ & 4 & $(1.76-3.66)$ \\
\hline 4 & Skin elasticity & $2.86(0.90)$ & 4 & $(1.96-3.76)$ \\
\hline 5 & Skin realism & $3.14(0.90)$ & 4 & $(2.24-4.00)$ \\
\hline 6 & Fat layer & $3.29(0.76)$ & 4 & $(2.53-4.00)$ \\
\hline \multicolumn{5}{|c|}{ Realism of Experience (Domain Mean $=3.19$ ) } \\
\hline 7 & Z plasty & $3.29(0.76)$ & 4 & $(2.53-4.00)$ \\
\hline 8 & V-Y & $3.29(0.76)$ & 4 & $(2.53-4.00)$ \\
\hline 9 & Rhombic flap & $3.14(0.90)$ & 4 & $(2.24-4.00)$ \\
\hline 10 & Rectangular advancement & $3.14(0.90)$ & 4 & $(2.24-4.00)$ \\
\hline 11 & Bilobe & $3.14(0.90)$ & 4 & $(2.24-4.00)$ \\
\hline 12 & O- $\mathrm{T}$ & $3.43(0.53)$ & 4 & $(2.90-3.96)$ \\
\hline 13 & Pinwheel & $3.43(0.53)$ & 4 & $(2.90-3.96)$ \\
\hline 14 & Note & $3.29(0.76)$ & 4 & $(2.53-4.00)$ \\
\hline 15 & Rehearsal & $3.43(0.79)$ & 4 & $(2.90-3.96)$ \\
\hline 16 & Flap mechanics & $3.14(0.90)$ & 4 & $(2.24-4.00)$ \\
\hline 17 & Material incision & $2.86(0.69)$ & 4 & $(2.17-3.55)$ \\
\hline 18 & Suturing & $2.71(0.95)$ & 4 & $(1.76-3.66)$ \\
\hline \multicolumn{5}{|c|}{ Performance (Domain Mean $=4.50$ ) } \\
\hline 19 & Z plasty & $4.57(0.53)$ & 5 & $(4.04-5.00)$ \\
\hline 20 & $V-Y$ & $4.57(0.53)$ & 5 & $(4.04-5.00)$ \\
\hline 21 & Rhombic flap & $4.43(0.79)$ & 5 & $(3.64-5.00)$ \\
\hline 22 & Rectangular advancement & $4.57(0.53)$ & 5 & $(4.04-5.00)$ \\
\hline 23 & Bilobe & $4.29(0.76)$ & 5 & $(3.53-5.00))$ \\
\hline 24 & 0-T & $4.57(0.53)$ & 5 & $(4.04-5.00$ \\
\hline 25 & Pinwheel & $4.57(0.53)$ & 5 & $(4.04-5.00)$ \\
\hline 26 & Note & $4.43(0.79)$ & 5 & $(3.64-5.00)$ \\
\hline \multicolumn{5}{|c|}{ Fidelity: Value (Domain Mean $=3.51$ ) } \\
\hline 27 & Please rate the value of the simulator as a training tool & $3.86(0.38)$ & 4 & $(3.48-4.00)$ \\
\hline 28 & $\begin{array}{l}\text { Please rate the value of the simulator as a competency } \\
\text { evaluation tool }\end{array}$ & $3.57(0.53)$ & 4 & $(3.04-4.00)$ \\
\hline 29 & $\begin{array}{l}\text { Please rate the value of the simulator as a rehearsal/ } \\
\text { practice tool }\end{array}$ & $3.43(0.79)$ & 4 & $(2.90-3.96)$ \\
\hline 30 & $\begin{array}{l}\text { Please rate the relevance of this simulator } \\
\text { to your practice }\end{array}$ & $3.57(0.79)$ & 4 & $(2.78-4.00)$ \\
\hline 31 & $\begin{array}{l}\text { Evaluation of the global improvements needed for } \\
\text { the simulator }\end{array}$ & $3.14(0.69)$ & 4 & $(2.45-3.83)$ \\
\hline
\end{tabular}

as a training tool, competency evaluation tool, and a rehearsal/ practice tool are suggestive of future success in medical education courses. In addition, the other highly rated areas and high ratings across the performance domain suggest that the facial flap is beneficial for a broad range of facial flap procedures.

For transportation purposes, which would be required for global health training, small facial flap simulators were used for validation. Small adjustments suggested by the experts, including a thinner skin layer and increased elasticity have been addressed in an iterative design. The adipose layer was adjusted following critiques to be softer by adding a silicone softener material. Silicone does not hold suture exactly in the same manner as skin does, but sufficiently emulates closure. Cost and manufacturability must be considered for evaluation of material choice when designing or adopting a training tool.

An overarching aim of our team is to shift the surgical learning curve outside of the operating room, while accelerating and enhancing surgical education. In a recent study, learning styles of 132 surgical residents were recorded to be multimodal (61\%), kinesthetic (17\%), aural (10\%), visual (7\%), and read/write $(5 \%) .{ }^{13}$ This suggests that surgical education cannot only be completed solely as an apprenticeship for all learners to gain the necessary skills required for surgical training. ${ }^{14}$

There are broad future applications for simulators like this one, with anatomical accuracy, lack of risk, and reusability. Current CAD design software uses CT or magnetic resonance imaging data to gain true anatomical features for models like 
this. The process we used is capable of designing and implementing simulators and biomedical devices that are anatomically accurate. Our group has longstanding experience in designing simulators and devices, including ideation and development of the tracheal splint used to treat tracheobronchomalacia. ${ }^{15}$ There are also further applications in medical education. Courses for new residents could lessen the learning curve for learning local facial flaps. International initiatives could focus on both resident and current physician training. Simulators like the local facial flap can also demonstrate proficiency criteria essential for education and evaluation.

\section{Conclusions}

The facial flap simulator is a simple solution to gaining increased confidence in surgical facial local flap procedures. With the ability to practice on the anatomical landmarks of facial features, residents have the opportunity to learn and practice on a simulator before progressing to patient procedures. This facial local flap simulator has application as an educational trainer, rehearsal model, and proof of proficiency tool.

\section{ARTICLE INFORMATION}

Accepted for Publication: January 10, 2019.

Published Online: April 25, 2019.

doi:10.1001/jamafacial.2019.0050

Author Contributions: Dr Zopf had full access to all of the data in the study and takes responsibility for the integrity of the data and the accuracy of the data analysis.

Study concept and design: Powell, Srinivasan,

Green, Zopf.

Acquisition, analysis, or interpretation of data: All authors.

Drafting of the manuscript: Powell, Srinivasan, Zopf. Critical revision of the manuscript for important intellectual content: All authors.

Statistical analysis: Powell, Srinivasan.

Obtained funding: Powell, Green, Zopf.

Administrative, technical, or material support

Srinivasan, Green, Zopf.

Study supervision: Srinivasan, Green, Kim, Zopf.

Conflict of Interest Disclosures: Dr Green reported a patent for an Airway splint. No other conflicts were reported.

Funding/Support: Allison R. Powell is funded by the T32 DC005356 NIH predoctoral research grant.

Role of the Funder/Sponsor: The National Institutes of Health had no role in the design and conduct of the study; collection, management, analysis, and interpretation of the data; preparation, review, or approval of the manuscript; and decision to submit the manuscript for publication.

Additional Contributions: We thank all of the experts who evaluated the simulator. We also thank Kimberly Cabrera and Djordje Jaksic, University of Michigan, for their help with manufacturing the facial flaps. They received undergraduate course credits for their contributions.

\section{REFERENCES}

1. Arora A, Lau LYM, Awad Z, Darzi A, Singh A, Tolley N. Virtual reality simulation training in otolaryngology. Int J Surg. 2014;12(2):87-94. doi:10. 1016/j.jjsu.2013.11.007

2. Gilmour A, Taghizadeh R, Payne CE. The educational hand and head: novel teaching tools in the design and execution of local flaps. J Plast Reconstr Aesthet Surg. 2012;65(7):981-982. doi:10. 1016/j.bjps.2011.11.044

3. Javia L, Sardesai MG. Physical models and virtual reality simulators in otolaryngology. Otolaryngol Clin North Am. 2017;50(5):875-891. doi:10.1016/j. otc.2017.05.001

4. Thone N, Winter M, García-Matte RJ, González C. Simulation in otolaryngology: a teaching and training tool. Acta Otorrinolaringol Esp. 2017;68(2): 115-120. English Edition. doi:10.1016/j.otorri.2016.04. 007

5. Naveed H, Hudson R, Khatib M, Bello F. Basic skin surgery interactive simulation: system description and randomised educational trial. $A d v$ Simul (Lond). 2018;3(1):14. doi:10.1186/s41077-018 0074-5

6. Reighard CL, Green K, Rooney DM, Zopf DA. Development of a novel, low-cost, high-fidelity cleft lip repair surgical simulator using computer-aided design and 3-dimensional printing [Published online November 01, 2018]. JAMA Facial Plast Surg. doi:10.1001/jamafacial.2018.1237

7. Mulford JS, Babazadeh S, Mackay N. Three-dimensional printing in orthopaedic surgery: review of current and future applications. ANZ J Surg. 2016;86(9):648-653. doi:10.1111/ans.13533
8. Vakharia VN, Vakharia NN, Hill CS. Review of 3-dimensional printing on cranial neurosurgery simulation training. World Neurosurg. 2016;88:188 198. doi:10.1016/j.wneu.2015.12.031

9. VanKoevering KK, Malloy KM. Emerging role of three-dimensional printing in simulation in otolaryngology. Otolaryngol Clin North Am. 2017;50 (5):947-958. doi:10.1016/j.otc.2017.05.006

10. VanKoevering KK, Hollister SJ, Green GE. Advances in 3-dimensional printing in otolaryngology: a review. JAMA Otolaryngol Head Neck Surg. 2017;143(2):178-183. doi:10.1001/ jamaoto.2016.3002

11. Berens AM, Newman S, Bhrany AD, Murakami C, Sie KC, Zopf DA. Computer-aided design and 3D printing to produce a costal cartilage model for simulation of auricular reconstruction. Otolaryngol Head Neck Surg. 2016;155(2):356-359. doi:10. 1177/0194599816639586

12. Ha JF, Morrison RJ, Green GE, Zopf DA. Computer-aided design and 3-dimensional printing for costal cartilage simulation of airway graft carving. Otolaryngol Head Neck Surg. 2017;156(6): 1044-1047.

13. Artino AR Jr, La Rochelle JS, Dezee KJ, Gehlbach $\mathrm{H}$. Developing questionnaires for educational research: AMEE Guide No. 87. Med Teach. 2014;36 (6):463-474. doi:10.3109/0142159X.2014.889814

14. Kim RH, Viscusi RK, Collier AN, et al. Learning preferences of surgery residents: a multi-institutional study. Surgery. 2018;163(4): 901-905. doi:10.1016/j.surg.2017.10.031

15. Zopf DA, Hollister SJ, Nelson ME, Ohye RG, Green GE. Bioresorbable airway splint created with a three-dimensional printer. N Engl J Med. 2013;368 (21):2043-2045 